\title{
What Future in Neutron Imaging?
}

\author{
Eberhard H. Lehmann* ${ }^{1}$, Danas Ridikas ${ }^{2}$, Nuno Pessoa Barradas ${ }^{2}$ \\ ${ }^{1}$ Paul Scherrer Institut, Laboratory for Neutron Scattering \& Imaging, CH-5232 Villigen PSI, \\ Switzerland \\ ${ }^{2}$ International Atomic Energy Agency (IAEA), Division of Physical and Chemical Sciences \\ eberhard.lehmann@psi.ch \\ * corresponding author
}

\begin{abstract}
Keywords: Neutron Imaging, Neutron Sources, Beam Ports, Neutron Detection, Image Processing
\end{abstract}

\begin{abstract}
We describe the current situation of the neutron imaging technology, based on known "user facilities" and projects at prominent neutron sources world-wide. Although this method has become highly accepted, there is a great potential for further methodical and technical progress. Continued access to most suitable beam ports and future neutron sources are keystones for the future of neutron imaging. Promising new methods and prominent new applications are stimulating this process.

\section{Introduction}

Neutron Imaging is today a well-established technique for scientific and technical applications. It is very complementary to similar X-ray methods and can often be used symbiotically [1]. The layout of a dedicated imaging beam line should be based on state-of-the-art technologies and the valuable experience of facility operators. The future of this technique will depend on the continuous access to best suitable beam ports at present and future useful neutron sources.

This paper starts with a "generic neutron imaging facility", will reflect the situation on neutron sources and their developments, have a look onto new facility projects and upgrades of existing ones, describe options for best facility utilization and highlight the methodical progress and other new options in neutron imaging.
\end{abstract}

\section{The generic neutron imaging facility}

As shown in Fig. 1, a generic neutron imaging (NI) facility consists of four major components: the neutron source, including moderation media and filters, the beam forming equipment (collimation), the sample environment and the neutron imaging detector.

Modern NI stations [2] have become quite complex and sophisticated systems if all modern trends in this technology should be involved. Depending on complexity level and desired performance, the investments required are in the range from some ten thousands to some ten millions of Euros [3].

The technical level of a NI installation depends on the lab strategy, framed by the funding, the major applications and the demands of the user community [4]. The available facilities can be categorized roughly into four classes:

1. Operational user labs, open for an international access by scientific and industrial partners

2. Operational in-house and test facilities, mainly used by own researchers for domestic projects 
3. On-going new NI installation projects or facility upgrade activities

4. Projects under considerations for potential new or upgrade facility installations

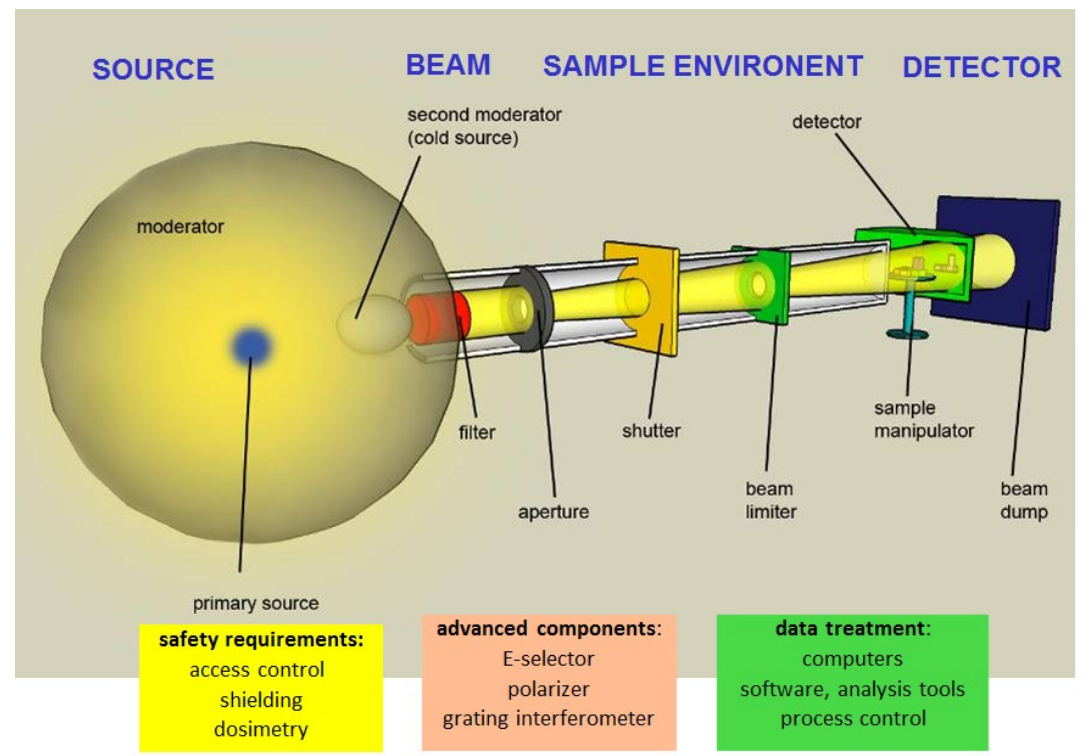

Fig. 1: $\quad$ Layout of a generic neutron imaging facility with the major components and supplementary features

The determining conditions underpinning the most advanced NI systems are:

- Well collimated (high L/D-ratio) neutron beam

- Beam size adequate to the sample dimensions

- High neutron beam intensity

- Narrow energy band (thermal or cold), well-known spectral conditions, necessary for quantification

- Low background from gamma rays or fast neutrons in the primary beam

- Flat beam profile

- No interference from back-scattered neutrons (and process gammas)

In general, a high intensity neutron beam is required to achieve the highest temporal, spatial or spectral resolution in a reasonable acquisition time. In addition, many more sophisticated techniques are possible in reasonable acquisition time when the intensity is suitable.

\section{Neutron source development}

From all options for the generation of neutrons, until now the research reactors remain the most common, flexible, powerful and even cost-efficient sources of neutrons. They are also by far the majority of the sources where NI stations are presently located and utilized. There exist a few intensive spallation neutron sources as well as other accelerator based neutron sources with lower output of well collimated beams of moderated neutrons. One notes separately that isotopic neutron sources have by far no chance to compete in NI performance when compared to the above mentioned accelerator or reactor based facilities. 
The development of the NI technology has to be seen in a global context. In order to develop, apply and utilize modern techniques, the access to well-suited beam ports is necessary. As a general trend, the number of appropriate neutron sources is decreasing in developed countries, but more are being installed in developing countries. On the other hand, the most advanced NI facilities are still situated in a few labs in developed countries. Therefore, the knowledge transfer towards the newly implemented facilities is essential for the progress in the field and broader access for usage of the technique.

Fig. 2 describes well the world-wide situation of operational research reactors as summarized in the IAEA Research Reactor data base [5]. From the currently running research reactors with a suitable power above $100 \mathrm{~kW}, 75$ facilities declare to perform "neutron radiography". Since no detailed specification is given in the data base for many facilities, it is difficult to estimate on which technological level these installations are.

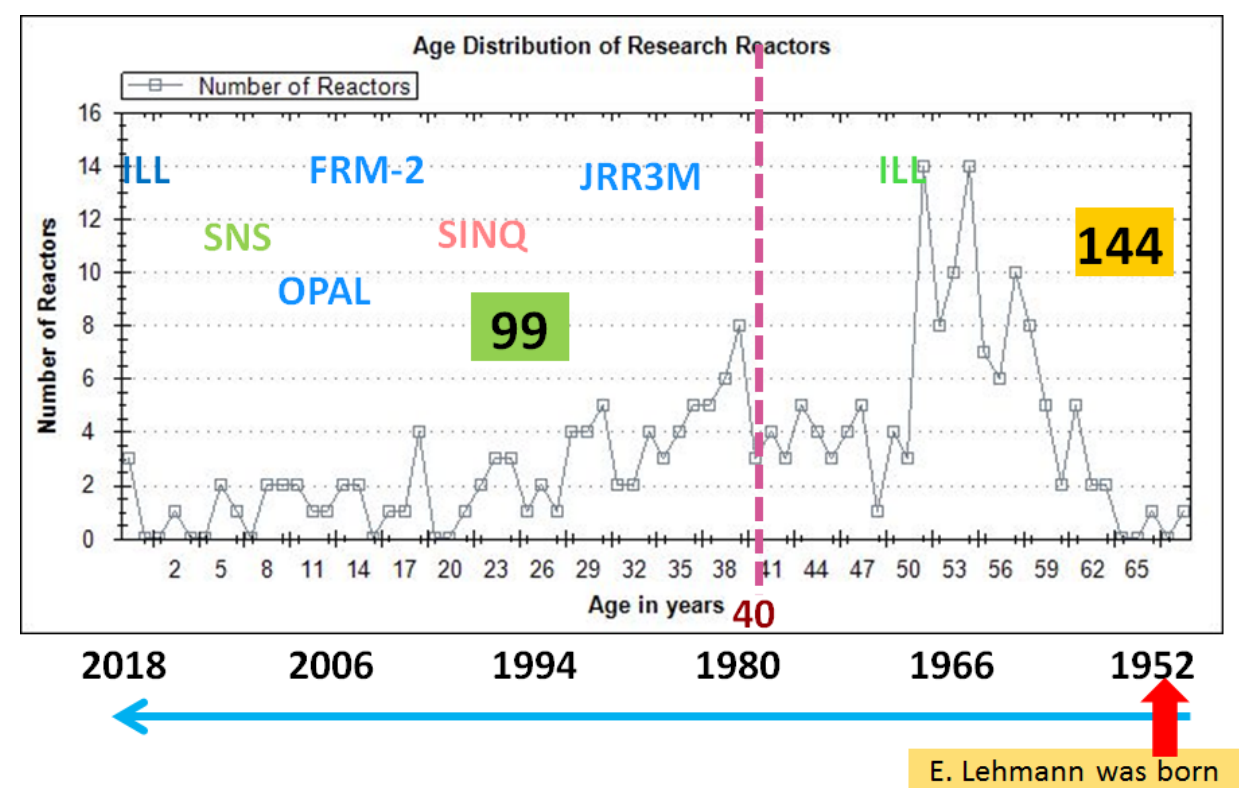

Fig. 2: $\quad$ Number of newly commissioned research reactors per year in an inverse time scale: more than 140 have an age of more than 40 years. Some famous sources are highlighted (ILL is indicated twice since NI started just now - 50 years after its startup); SINQ and SNS are not reactors, but spallation neutron sources - shown for comparison. The data are taken from the IAEA RR data base, see: https://nucleus.iaea.org/rrdb.

The show examples are by far not complete, but indicate some milestones for the imaging community.

A more pragmatic way for data achievement about NI facilities has been made by the "International Society for Neutron Radiography (ISNR)" survey as published on their homepage [6]. A list of "user facilities" can be found in [7], but an update will be given in the appendix.

Only few research reactor installations are expected to come to operation in the next years, while aged reactors will continue to shut down for different reasons. On the other hand, all spallation sources (ISIS, JPARC, SNS, ESS) involve NI as a key technology in dedicated projects, while SINQ already operates a few different stations [8] since many years with great success. 
The situation within Europe is illustrated by Fig. 3 and the number of NI facilities (running and projected) is added. A similar analysis is not available for the rest of the world in the same quality.

Given the fact that new reactor based sources are not presently being built or planned in the Western world, there are initiatives to evaluate and design accelerator based neutron sources with specific performance, e.g. "high brilliance" [9] customized for specific applications. Also in such cases, NI installations are or could be foreseen from the beginning.

\section{New installations and upgrades of NI facilities}

Most of the prominent and powerful neutron sources have been "taken" by the neutron scattering community, by irradiation experiments for nuclear technologies, including isotope production and silicon doping. Therefore, only a few most suitable beam ports remained available and used for NI facilities in the past.

The situation has changed slightly after the development, at the end of last century, of digital imaging detector systems with superior performance compared to film based methods. It was possible to make very competitive installations ready in Japan, Europe and America, and more recently in Australia. Based on that progress, the family of "user facilities" has been established which have a similar operational approach now like neutron scattering instruments.

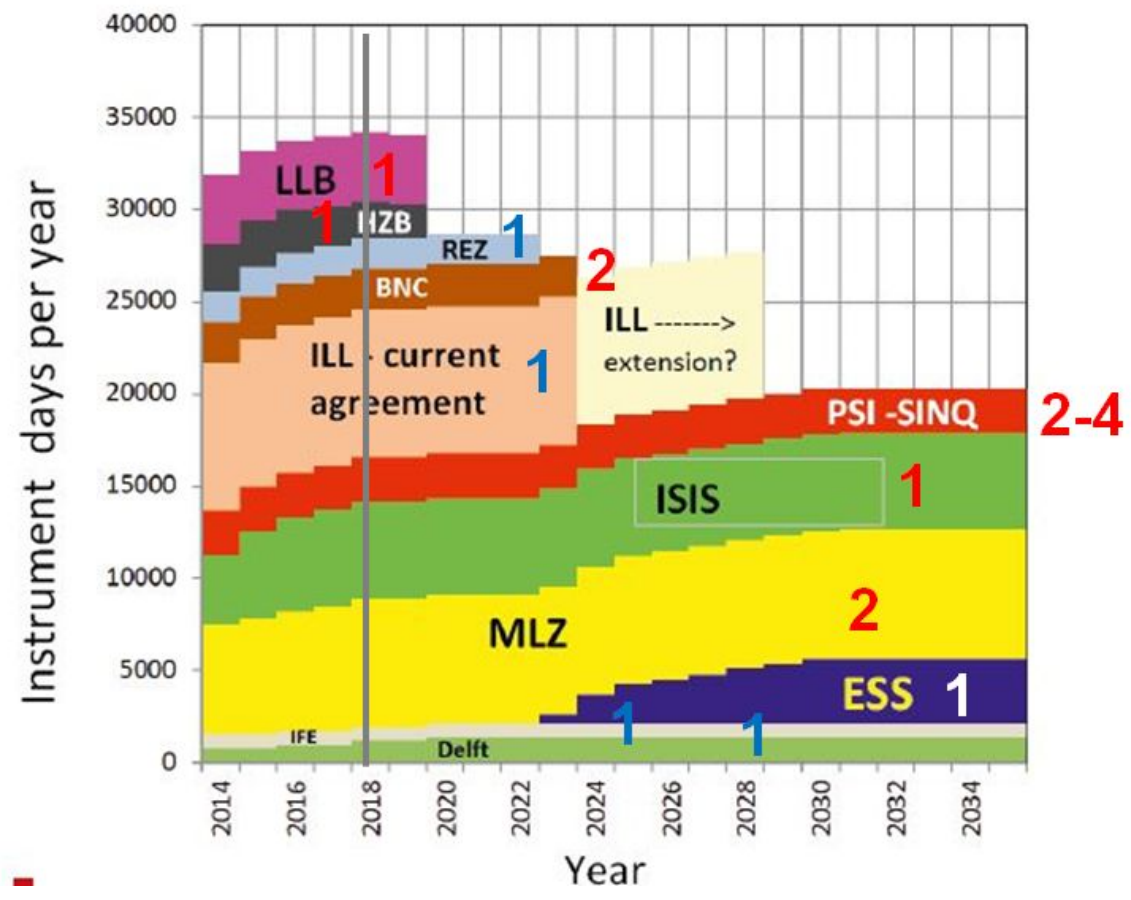

Fig. 3: Neutron sources in Europe (data base: [6]); the numbers indicate existing (red) and planned NI facilities

New sources tried to follow this trend already at the planning stage, including CARR in China, and planned NI facilities in reactors in Argentina, Jordan and Brazil.

Other countries, operating a research reactor for a long time, intend now to rebuild beam ports into NI stations or intend to make a major upgrade, e.g. South Africa and Indonesia. The level of performance these new setups will have depends on the financial situation, the involved 
(qualified) manpower and the particular source conditions. Tables 1 to 3 summarize the particular activities were the categories 2-4 as mentioned above are taken.

Table 1: $\quad$ In-house and test facilities, mainly for own projects

\begin{tabular}{|l|l|l|}
\hline country & source & situation \\
\hline Thailand & reactor TTR-1, 2 MW & NI exists, limited user program \\
\hline India & reactors at BARC & high potential, but limited communication with NI community \\
\hline Indonesia & reactor RSG-GAS, 30 MW & NI exists, limited user program \\
\hline Canada & reactor McMaster, $5 \mathrm{MW}$ & commercial activities, limited research \\
\hline France & reactor Orphee, $14 \mathrm{MW}$ & facility IMAGINE, limited user operation, shutdown after 2019 \\
\hline Europe & reactor @ ILL, 58 MW & a facility at cold beam port D50 under preparation, some users \\
\hline Egypt & reactor ETRR-2, 22 MW & NI exists, limited user program \\
\hline Brazil & reactor IEA-R1, 2 MW & NI exists, limited user program \\
\hline Bangladesh & BAEC TRIGA reactor, 3 MW & NI exists, limited user program \\
\hline Russia & several research reactors & IR-8, IRT-T, some NI exists \\
\hline Poland & reactor MARIA & NI exists, limited user program \\
\hline
\end{tabular}

Table 2: $\quad$ Running NI installation projects and upgrade activities

\begin{tabular}{|l|l|l|}
\hline \multicolumn{1}{l|}{ country } & source & situation \\
\hline Argentina & reactor RA-10, 30 MW & NI facility as day-one installation, completion in 2020 \\
\hline Brazil & new reactor like RA-10 & planned and funding provided \\
\hline Czech Republic & reactor LVR-15, 10 MW & NI facility with limited performance, upgrade intensions \\
\hline China & reactor CARR, 60 MW & two imaging facilities under preparation \\
\hline Norway & reactor JEEP-II, 2 MW & NI facility upgrade \\
\hline Netherlands & reactor HOR, 5 MW & NI facility planned, preliminary setup exists \\
\hline South Africa & reactor SAFARI, 20 MW & upgrade of the SANRAD facility \\
\hline South Korea & reactor HANARO, 30 MW & operational again, utilization programme not yet started \\
\hline USA & Idaho RR, 250 kW & upgrade program for digital NI \\
\hline
\end{tabular}

Table 3: $\quad$ Potential options and intentions for installations

\begin{tabular}{|l|l|l|}
\hline country & source & situation \\
\hline Marocco & TRIGA reactor, $2 \mathrm{MW}$ & NI facility planned \\
\hline Malaysia & TRIGA reactor, 1 MW & NI facility exists, starting with digital system, limited communication \\
\hline Algeria & reactor NUR, 1 MW & NI facility exists \\
\hline Chile & reactor RECH 2, 10 MW & reactor out of operation, lack of manpower for NI \\
\hline Peru & reactor RP-10, 10 MW & NI possible \\
\hline Slovenia & TRIGA reactor, $250 \mathrm{~kW}$ & NI program stopped \\
\hline Uzbekistan & reactor WWR-SM, 10 MW & NI not existing, but under consideration. \\
\hline Russia & reactor PIK, 100 MW & operation unclear \\
\hline Jordan & reactor JRTR, 5 MW & NI facility planned, reactor operational \\
\hline Mexico & reactor TRIGA, 1 MW & NI considered \\
\hline
\end{tabular}

\section{Best utilization}

With the improvement of the detector technology also the utilization of the beam lines has been increased enormously. This gives the opportunity to perform much more investigations in shorter time while with an increased data volumes (towards the Tera-Byte region already).

In this manner, partners from different research areas can be invited for dedicated studies, with customized infrastructure and equipment. The same is valid for industrial partners on a 
commercial basis. Prominent cases are studies for fuel cells, batteries, particulate filters or electronic devices [10].

Since the number of such "user facilities" (see appendix) is still low and there are planned or unplanned shutdowns of these sources, a good communication and coordination between the facility operators will help to serve the increasing user community best.

\section{Methodical developments \& new applications}

Starting with simple radiography studies many more advanced techniques have been developed and were introduced into the common user program in the meantime. It started with neutron tomography on a competitive level with X-rays and involved the fully quantitative analysis such as for precise water determination.

A very recent approach is "grating interferometry" which enables to study phase contrast and dark image features in samples with structures in the micro-meter range, linking to small-angle scattering studies.

In the dynamic imaging, either high frame rates are possible now (depending on the beam intensity, up to $100 \mathrm{~Hz}$ and more) or triggered stroboscopic investigations of repetitive processes. Due to the magnetic moment of neutrons, the separation of one of the two spin states (polarization) enables studies of magnetic properties on the macroscopic scale [11].

The separation of tiny energy bands of the initial beam has many advantages, in particular for crystalline materials with pronounced Bragg scattering behavior. It has been realized to study textures, crystal orientations and even internal stress with energy-resolved options. The use of time-of-flight techniques at pulsed sources will provide even better conditions in this respect.

\section{Conclusions}

Neutron imaging has made an enormous progress in the past years, but in limited number of labs only. Now, there is a challenging need to transfer this know-how to other suitable neutron sources and to increase the network within the neutron imaging community. The access to prominent and new installations is mandatory for the progress and strengthening of neutron imaging in the future.

\section{References}

[1] A. Kaestner et al., Combined neutron and X-ray imaging on different length scales, Proc. 6th Conference on Industrial Computed Tomography, Wels, Austria (iCT 2016)

[2] E. Lehmann, D. Ridikas, Status of Neutron Imaging - Activities in a Worldwide Context, Physics Procedia, Volume 69, 2015, Pages 10-17. https://doi.org/10.1016/j.phpro.2015.07.001

[3] IAEA TECDOC Series, Commercial Products and Services of Research Reactors, IAEATECDOC-1715 (2013)

[4] IAEA Nuclear Energy Series NG-T-3.16, Strategic Planning for Research Reactors (2017)

[5] https://nucleus.iaea.org/rrdb.

[6]https://ec.europa.eu/research/infrastructures/pdf/esfri/publications/esfri_neutron_landscape_gr oup-report.pdf, page 69

[7] http://www.isnr.de/index.php/facilities/user-facilities 
[8] E. Lehmann, New neutron imaging techniques to close the gap to scattering applications, Journal of Physics: Conference Series, Volume 746, Number 1. https://doi.org/10.1088/17426596/746/1/012070

[9] T. Cronert et al., High brilliant thermal and cold moderator for the HBS neutron source project Jülich, Journal of Physics: Conference Series, Volume 746, Number 1. https://doi.org/10.1088/1742-6596/746/1/012036

[10] L. Donzel et al., Space-resolved study of binder burnout process in dry pressed $\mathrm{ZnO}$ ceramics by neutron imaging, Journal of the European Ceramic Society, Volume 38, Issue 16, Pages 5448-5453. https://doi.org/10.1016/j.jeurceramsoc.2018.08.017

[11] N. Kardjilov et al., Three-dimensional imaging of magnetic fields with polarized neutrons, Nature Physics 4, 399 - 403 (2008). https://doi.org/10.1038/nphys912 


\section{Appendix: NI user facilities world-wide}

\begin{tabular}{|c|c|c|c|c|c|c|c|}
\hline country & site & institution & facility & $\begin{array}{l}\text { neutron } \\
\text { source }\end{array}$ & spectrum & $\begin{array}{c}\text { power } \\
\text { [MW] }\end{array}$ & status \\
\hline Australia & Sydney & ANSTO & DINGO & $\begin{array}{l}\text { OPAL } \\
\text { reactor }\end{array}$ & thermal & 20 & operational \\
\hline Germany & $\begin{array}{l}\text { Munich- } \\
\text { Garching }\end{array}$ & TU Munich & ANTARES & $\begin{array}{l}\text { FRM-2 } \\
\text { reactor }\end{array}$ & cold & 25 & operational \\
\hline Germany & $\begin{array}{l}\text { Munich- } \\
\text { Garching }\end{array}$ & TU Munich & NECTAR & FRM-2 & fast & 25 & operational \\
\hline Germany & Berlin & $\mathrm{HZB}$ & CONRAD & $\begin{array}{l}\text { BER-2 } \\
\text { reactor }\end{array}$ & cold & 10 & operational \\
\hline Hungary & Budapest & KFKI & NORMA & $\begin{array}{l}\text { WWS-M } \\
\text { reactor }\end{array}$ & cold & 10 & operational \\
\hline Hungary & Budapest & KFKI & NRAD & $\begin{array}{l}\text { WWS-M } \\
\text { reactor }\end{array}$ & thermal & 10 & operational \\
\hline Japan & Kyoto & $\begin{array}{l}\text { Kyoto } \\
\text { University }\end{array}$ & $\begin{array}{l}\text { imaging } \\
\text { beamline }\end{array}$ & MTR reactor & thermal & 5 & standby \\
\hline Japan & Tokai & JAEA & $\begin{array}{l}\text { imaging } \\
\text { beamline }\end{array}$ & $\begin{array}{l}\text { JRR-3M } \\
\text { reactor }\end{array}$ & thermal & 20 & standby \\
\hline Japan & Tokai & JAEA & RADEN & $\begin{array}{l}\text { JPARC } \\
\text { spallation }\end{array}$ & cold & 0.5 & operational \\
\hline Korea & Daejon & KAERI & $\begin{array}{l}\text { imaging } \\
\text { beamline }\end{array}$ & $\begin{array}{l}\text { HANARO } \\
\text { reactor }\end{array}$ & thermal & 30 & standby \\
\hline Russia & Dubna & JINR & $\begin{array}{l}\text { imaging } \\
\text { beamline }\end{array}$ & $\begin{array}{l}\text { IBR-2M } \\
\text { pulsed } \\
\text { reactor }\end{array}$ & thermal & 2 & operational \\
\hline Switzerland & Villigen & PSI & NEUTRA & $\begin{array}{l}\text { SINQ } \\
\text { spallation }\end{array}$ & thermal & 1 & operational \\
\hline Switzerland & Villigen & PSI & ICON & $\begin{array}{l}\text { SINQ } \\
\text { spallation }\end{array}$ & cold & 1 & operational \\
\hline UK & Oxfordshire & Rutherford Lab & IMAT & $\begin{array}{l}\text { ISIS } \\
\text { spallation }\end{array}$ & cold & 0.3 & operational \\
\hline USA & Gaithersburg & NIST & BT-2 & $\begin{array}{l}\text { NBSR } \\
\text { reactor }\end{array}$ & thermal & 20 & operational \\
\hline USA & Gaithersburg & NIST & NG-6 & $\begin{array}{l}\text { NBSR } \\
\text { reactor }\end{array}$ & cold & 20 & operational \\
\hline USA & Oak Ridge & ORNL & CG-1D & HFIR reactor & cold & 85 & operational \\
\hline South Africa & Pelindaba & NECSA & SANRAD & $\begin{array}{l}\text { SAFARI } \\
\text { reactor }\end{array}$ & thermal & 20 & standby \\
\hline
\end{tabular}

